\title{
VNREDSAT-1: BƯỚC ĐẦU LÀM CHỦ CÔNG NGHỆ VỆ TINH NHỎ QUAN SÁT TRÁI ĐÂTT CỦA VIẸT NAM
}

\author{
ThS. HOÀNG TH! THU HÀ, TS. PHAMM MINH HẢI \\ Viện Khoa học Đo đạc và Bản đồ
}

\section{Tóm tắt:}

Vệ tinh VNREDSat-1 là vệ tinh quang học quan sát Trái đất đầu tiên của Việt Nam. Đây là mốc đánh dấu sự gia nhập của Việt Nam vào nhóm 25 nước sở hữu vệ tinh viễn thám trên thế giới. Chủ động cung cấp số lượng lớn ảnh vệ tinh quang học có độ phân giải cao, VNREDSat-1 sẽ đảm bảo khả năng đáp ứng đầy đủ nhu cầu sư dụng ảnh viễn thám cho các mục tiêu khoa học và phát triển công nghệ phục vụ công tác giám sát tài nguyên thiên nhiên và môi trường ở Việt Nam.

\section{Giới thiệu chung}

$\mathrm{V}$ ệ tinh VNREDSat-1 (Vietnam Natural Resources, Environment and Disaster-monitoring Satellite-1) là vệ tinh quang học quan sát Trái đất đầu tiên của Việt Nam. Vệ tinh đã được phóng lên quỹ đạo thành công ngày $7 / 5 / 2013$ (theo giờ Việt Nam) từ sân bay vũ trụ Kourou, Guyana, thuộc Pháp. Đây là sự kiện có ý nghĩa quan trọng đánh dấu sự phát triển công nghệ vệ tinh viễn thám của Việt Nam.

VNREDSat-1 có nhiệm vụ chủ động cung cấp số lượng lớn ảnh vệ tinh quang học có độ phân giải cao cho các bộ, ngành, tỉnh, thành phố, các cơ quan nghiên cứu, các trường đại học có nhu cầu sử dụng nhằm tăng khả năng giám sát tài nguyên thiên nhiên, môi trường, ứng phó với thảm hoạ thiên nhiên, biến đổi khí hậu, phục vụ các mục tiêu phát triển kinh tế-xã hội và đảm bảo an ninh-quốc phòng.

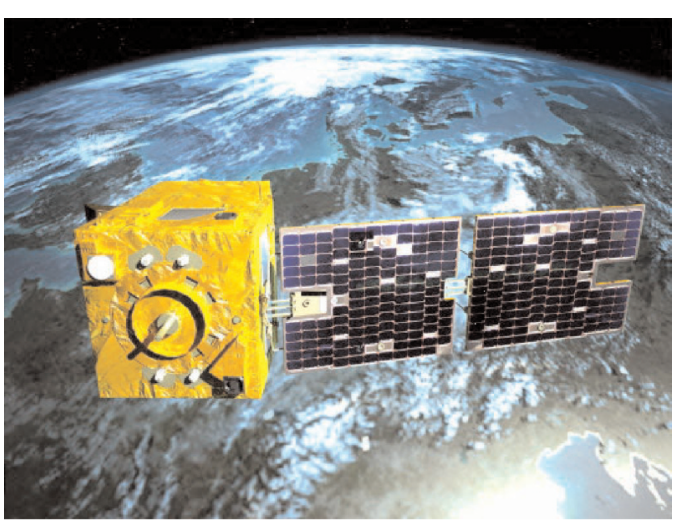

Hình 1: Hình ảnh vệ tinh VNREDSat-1 hoạt động trên quỹ đạo

(Nguồn: astrium.eads.net)

Cho tới nay, đã có nhiều bài báo giới thiệu thông tin về việc phóng vệ tinh mà chưa đề cập đến những thông tin khoa học của vệ tinh VNREDSat-1. Bài báo này có mục tiêu cung cấp thông tin khoa học về vệ tinh VNREDSat-1, được thể hiện ở 2 nội dung chính là: Giới thiệu về thông số kỹ thuật và sản phẩm ảnh chụp của vệ tinh VNREDSat-1, các trạm thu và điều hành vệ tinh VNREDSat-1. 


\section{Thông số kỹ thuật và sản phẩm}

Chỉ nặng $120 \mathrm{~kg}$ và có kích thước $60 \times 60 \times 100 \mathrm{~cm}$, nhưng vệ tinh VNREDSat-1 đảm trách khối lượng công việc khổng lồ, bao gồm theo dõi tài nguyên, quản lý môi trường, giám sát thiên tai trên toàn lãnh thổ Việt Nam với thời gian hoạt động là 5 năm.

Đây là vệ tinh nằm trong nhóm các vệ tinh siêu nhỏ (nhóm vệ tinh có trọng lượng dưới $200 \mathrm{~kg}$ ). Vệ tinh sử dụng hệ thống phụ chuyển dữ liệu AstroSat-100 của EADS Astrium (một phiên bản trên nền công nghệ mới Myriade dùng cho hoạt động thu và truyền dữ liệu các vệ tinh dưới $200 \mathrm{~kg}$ ) cho phép dễ dàng truy cập đến tất cả các thiết bị trong hệ thống vệ tinh. VNREDSat-1 hoạt động nhờ các tấm pin năng lượng mặt trời nên quỹ đạo bay của nó đồng bộ với quỹ đạo quay của Trái đất. Vệ tinh sử dụng 2 hệ thống phát điện là dàn pin mặt trời $(\mathrm{GaAs}$; $180 \mathrm{~W}$ EOL) và pin Li-ion $15 \mathrm{~A}$. Nhằm ổn định quỹ đạo bay vệ tinh trên độ cao 680 $\mathrm{km}$, hệ thống đẩy sử dụng nhiên liệu hóa học $\mathrm{N}_{2} \mathrm{H}_{4}$ được sử dụng đảm bảo $\Delta \mathrm{V}=70$ $\mathrm{m} / \mathrm{s}$. Vệ tinh được thiết kế hoạt động thăng bằng theo 3 trục và được trang bị các bộ phận như: thiết bị chụp ảnh, 3 bộ cảm biến mặt trời, 1 bộ cảm biến sao, 1 bộ cảm biến từ trường, IMU (Inertial Measurement Unit thiết bị ghi lại thông tin hoạt động của vệ tinh), thiết bị GPS định vị vị trí vệ tinh. (Xem hinh 2)

Thiết bị chụp ảnh sử dụng bộ cảm quét ảnh kiểu Pushbroom thường dùng trên các vệ tinh quang học với trọng lượng khoảng $18 \mathrm{~kg}$. Bộ phận quang học sử dụng thiết bị kính viễn vọng Korsch với đường kính của lỗ mở ống kính là 200 mm, độ dài tiêu cự là $2131 \mathrm{~mm}$. Dữ liệu kênh chụp phổ được truyền tải với tốc độ $60 \mathrm{Mbit} / \mathrm{s}$ với bộ nhớ lưu trữ từ 64 đến 79 Gbit BOL ở trạng thái không nén.

Chu trình từ quét ảnh đến ghi ảnh được thực hiện qua 3 phần chính đó là: (1) bộ nhận tín hiệu, (2) thiết bị hội tín hiệu, và (3) thiết bị ghi tín hiệu. Ở (3), tín hiệu được nhận và mã hóa thành giá trị 12 bit, sau đó được xử lý tức thời (real-time processing) và lưu vào bộ nhớ. (Xem hình 3)

Sản phẩm chụp ảnh ở kênh toàn sắc (PAN) và 4 kênh đa phổ (MS). Thời gian vệ tinh bay chụp lặp lại là 3 ngày.

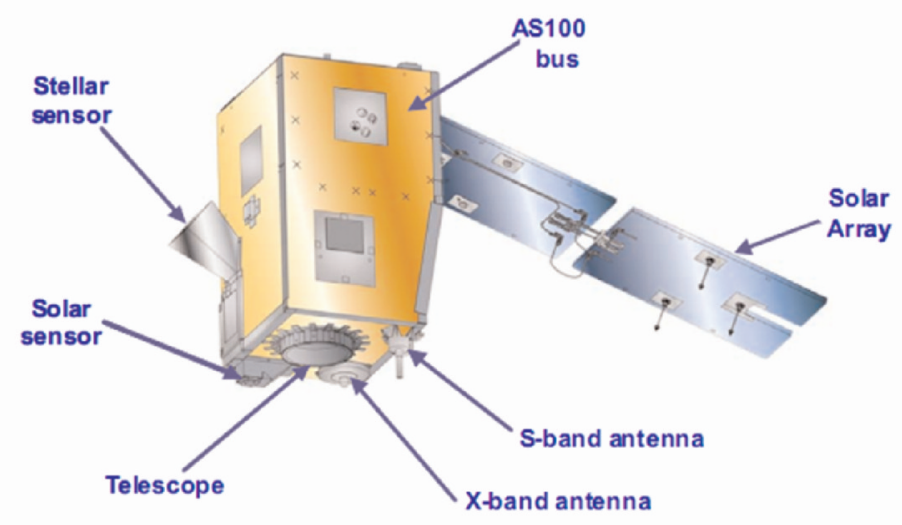

Hình 2: Tổng quan về vệ tinh VNREDSat-1 và một số thành phần khác (Nguồn:EO portal Directory) 


\begin{tabular}{|l|l|l|}
\hline Ảnh chụp & $\begin{array}{l}\text { Độ phân giải } \\
\text { không gian } \\
\text { (mét) }\end{array}$ & Băng phổ \\
\hline $\begin{array}{l}\text { Ảnh toàn sắc } \\
\text { (PAN) }\end{array}$ & 2.5 & $0.45-0.75 \mu \mathrm{m}$ \\
\hline & & $\begin{array}{l}\text { B1: } 0.45-0.52 \mu \mathrm{m} \\
\text { B2: } 0.53-060 \mu \mathrm{m} \\
\text { B3: } 0.62-0.69 \mu \mathrm{m} \\
\text { B4: } 0.76-0.89 \mu \mathrm{m} \\
\text { (cận hồng ngoại) }\end{array}$ \\
\hline $\begin{array}{l}\text { Ảnh đa phổ } \\
\text { (MS) }\end{array}$ & 10 & \\
\hline
\end{tabular}

\section{Quỹ đạo bay của VNREDSat-1}

Quỹ đạo đi lên và đi xuống của vệ tinh được thể hiện ở hình 4. (Xem hình 4)

Quỹ đạo bay của vệ tinh trong 1 ngày được mô tả ở hình 5. (Xem hình 5)

Quỹ đạo bay của vệ tinh trong 3 ngày được mô tả ở hình 6 , vệ tinh có khả năng chụp ảnh trên phạm vi thế giới. (Xem hình 6)

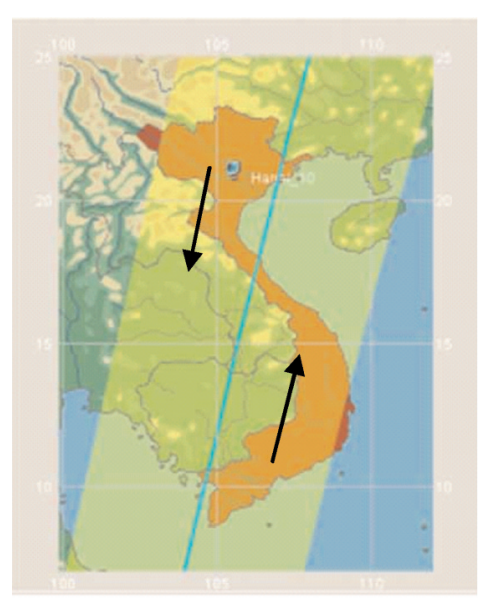

Hình 4: Quỹ đạo đi lên và đi xuống của vệ tinh (Nguồn: VAST)

\section{Trạm thu mặt đất}

Tại Việt Nam, 3 cơ sở mặt đất để điều hành, tiếp nhận và xử lý tín hiệu ảnh vệ tinh đã được triển khai chuẩn bị cho quá trình tiếp nhận và vận hành vệ tinh VNREDSat-1 gồm: Trung tâm điều hành (Trạm thu nhận kênh S) đặt tại khuôn viên Viện Hàn lâm Khoa học và Công nghệ Việt Nam; Trạm thu

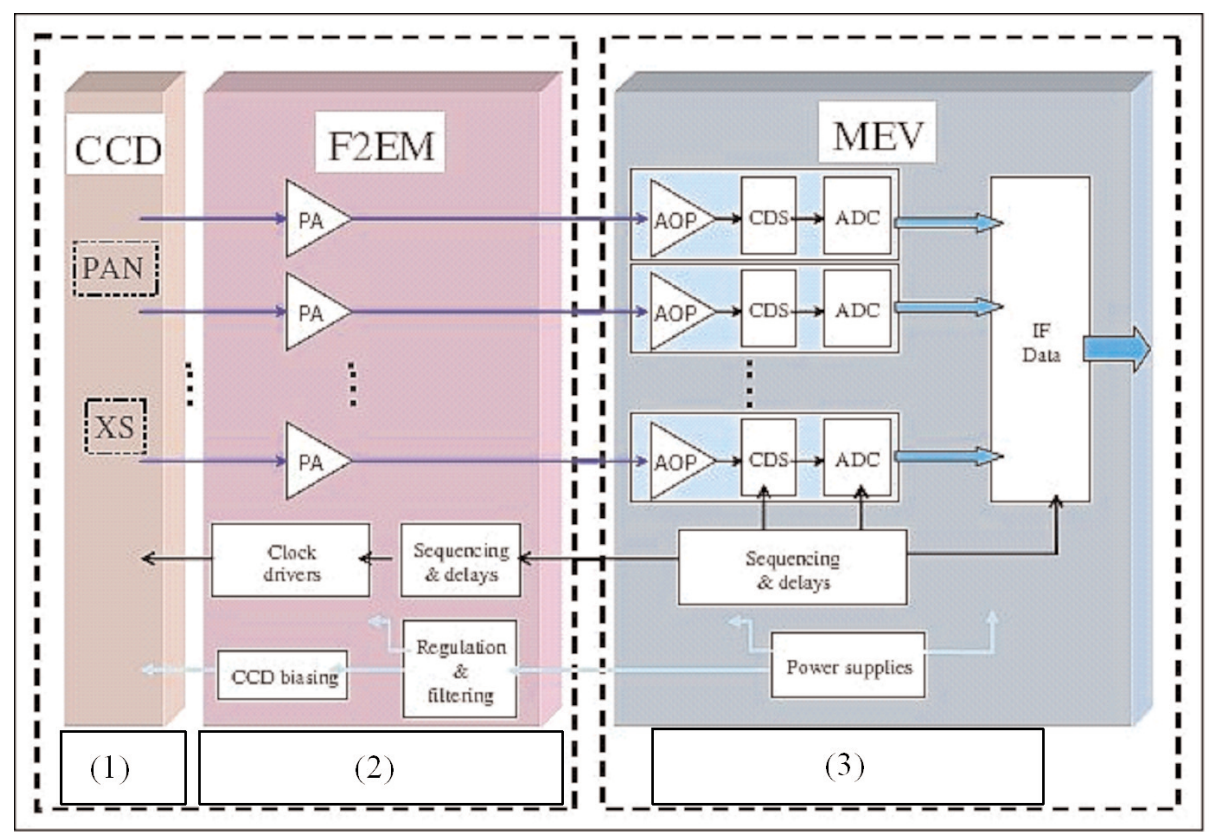

Hình 3: Quy trình sử lý dữ liệu (Nguồn: EADS Astrium SAS) 


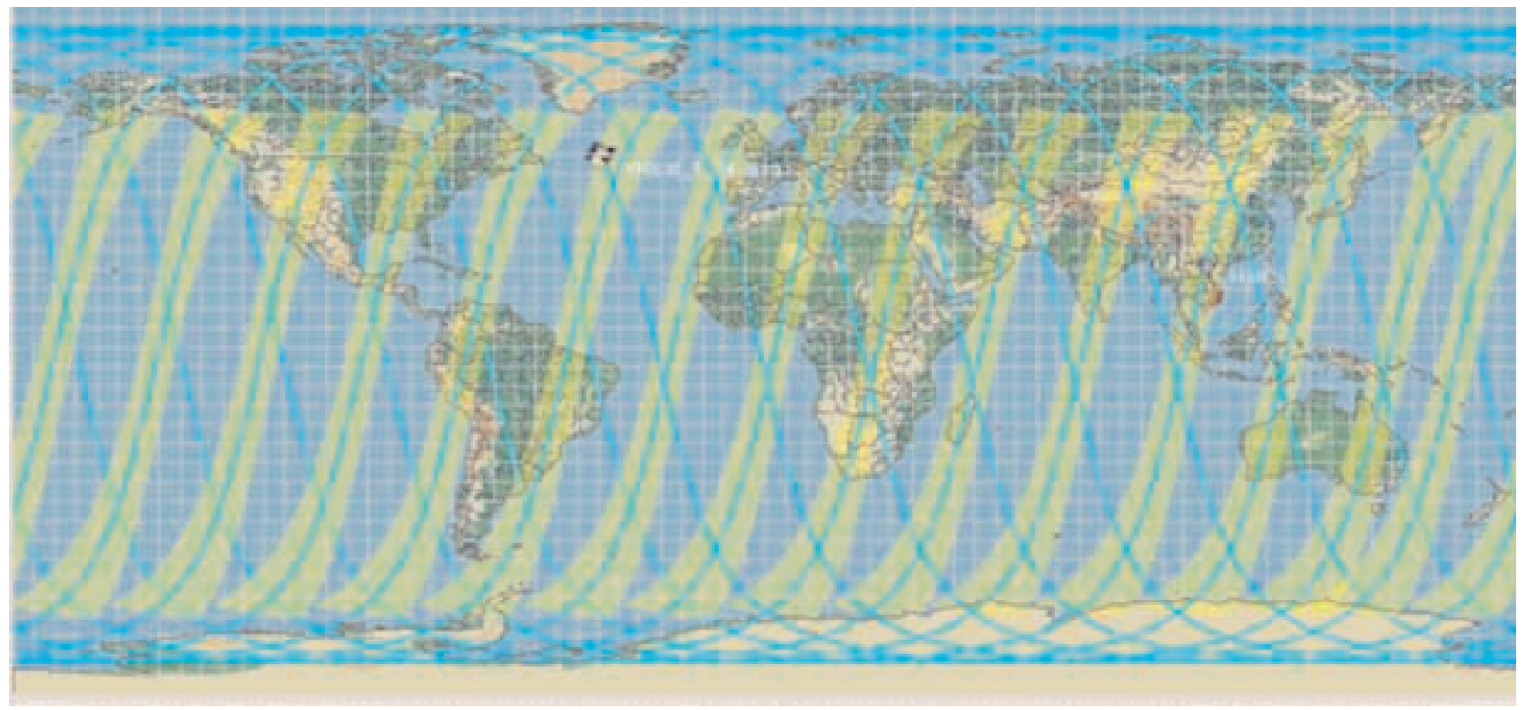

Hình 5: Mô tả quỹ đạo bay vệ tinh trong 1 ngày (Nguồn: VAST)

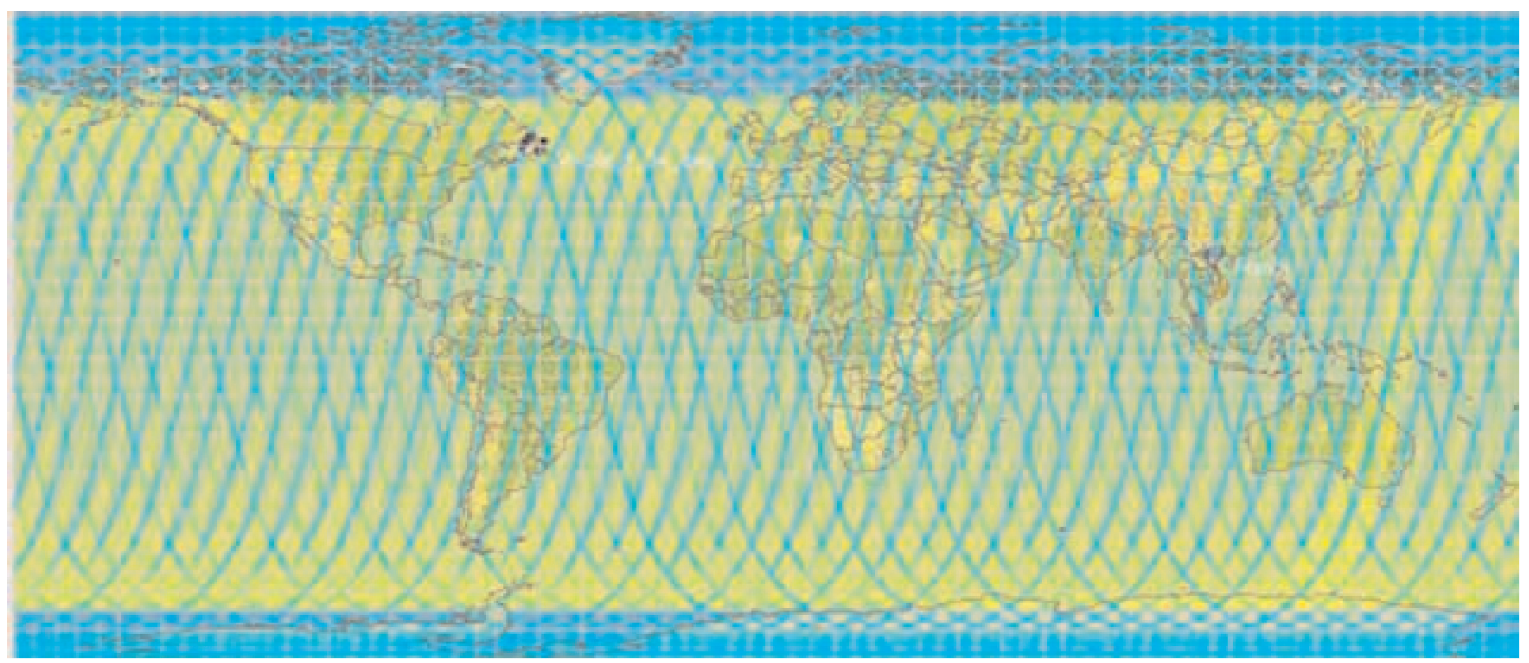

Hình 6: Mô tả quỹ đạo bay vệ tinh trong 3 ngày (Nguồn: VAST) 
phát tín hiệu điều khiển vệ tinh đặt tại Khu công nghệ cao Hòa Lạc; Trạm thu ảnh vệ tinh (Trạm thu nhận kênh $X$ ) đặt tại Trung tâm Viễn thám Quốc gia (Bộ Tài nguyên và Môi trường). Dự kiến khi đi vào hoạt động, mỗi ngày vệ tinh sẽ chụp được khoảng 100 ảnh, kích thước $20 \times 20 \mathrm{~cm}$. (Xem hình 7)

\section{Kết luận}

Vê tinh VNREDSat-1 là vê tinh viễn thám đầu tiên ở Việt Nam. Với khối lượng ảnh chụp lớn, các sản phẩm ảnh chụp sẽ hứa



Hình 7: Tổng quan về các bộ phận của dụ̣ án trạm thu VNREDSat-1 (Nguồn: VAST) 
hẹn khả năng đáp ứng cho các nhu cầu sư dụng ảnh viễn thám cho cả hai mục tiêu khoa học - công nghệ và kinh tế - xã hội ở Việt Nam. Theo Chiến lược nghiên cứu và ứng dụng công nghệ vũ trụ đến năm 2020 của Chính phủ, một trong những mục tiêu được đề ra là Việt Nam làm chủ công nghệ vệ tinh nhỏ. Việt Nam chính thức trở thành nước thứ năm trong khu vực có vệ tinh viễn thám sau Thái Lan, Indonesia, Malaysia, Singapore, gia nhập 1 trong 25 nước sở hữu vệ tinh viễn thám trên thế giới. Dự án có thể được coi là bước đi đầu tiên đến quá trình làm chủ vệ tinh. Đây là sự kiện có ý nghĩa quan trọng về mặt khoa học công nghệ, tiếp tục thể hiện và khẳng định chủ quyền quốc gia Việt Nam trong không gian, góp phần xác định vị thế của Việt Nam trong quá trình hội nhập với thế giới, đặc biệt trong lĩnh vực khai thác khoảng không vũ trụ vì các mục đích hòa bình, phục vụ lợi ích con người. $O$

\section{Tài liệu tham khảo}

[1]. VNREDSat-1A (Vietnam Natural Resources, Environment and Disaster-monitoring Satellite-1A), URL:https://directory.eoportal.org/web/eopo rtal/satellite-missions/v-w-x-y-z/vnredsat-1, truy cập ngày 5 tháng 6 năm 2013.

[2]. Charles Koeck and Didier Radola, 2011. "AstroSAT 100 : Microsatellite solution for high resolution remote sensing systems". Hội nghị quốc tế về vũ trụ lần 62 từ ngày 3 đến ngày 7 tháng 10 năm 2011 tại Thành phố Cape Town, Nam Phi. Trang: IAC-11B4.4.4.

[3]. Nguyễn Khoa Sơn, 2010. "Space Technology in Vietnam: 2010 Country Report". Hội nghị APRSAF-17 (17th Session of the Asia-Pacific Regional Space Agency Forum) từ ngỳa 23 đến 26 tháng 11 năm 2010 tại thành phố Melbourne, Úc URL:http://www.aprsaf.org/data/aprsaf17_d ata/D3-1330_N_Khoa_Son.pdf, truy cập ngày 5 tháng 6 năm 2013.

[4]. Bùi Trọng Tuyên và Phạm Minh Tuấn, 2012. "VNREDSat-1 Vietnam's first earth observation satellite system". O

\section{Summary}

VNREDSAT-1: THE FIRST STEP TO OWN THE SMALL EARTH OBSERVATION SATELLITE TECHNOLOGY OF VIETNAM

\section{MSc. Hoang Thi Thu Ha, Dr. Pham Minh Hai - Institute of Geodesy and Cartography}

VNREDSat-1 is the first Vietnam's earth observation optical satellite. This event make Vietnam become one of 25 countries in the world has remote sensing satellite. With a great amount of high resolution optical satellite images, VNREDSat-1 will satisfy the demand for the development of science and technology in the field of environment monitoring in Vietnam. $\bigcirc$

\section{Ngày nhận bài 20/5/2013.}

